The Geneva Papers on Risk and Insurance, 20 (No. 77, October 1995) 509-516

\title{
The Challenge of Educating the Leaders of Tomorrow*
}

\author{
by Antonio M. Borges**
}

Management education is evolving quite rapidly, as most of us understand that what was required to be an effective manager in the past may not be quite the same as what is necessary today. And the world of insurance is also changing quite fast, moving in directions which are quite promising in terms of additional opportunities for business, but which also bring new challenges and risks, for which we will have to be prepared.

To try and bring together my experience as an economist and as the Dean of Europe's premier business school, I would propose to discuss briefly the changes in the economic environment which can be expected to bring new opportunities and new challenges to the insurance sector; to refer to the responses which can already be observed from the insurance companies and to new directions which insurers will have to consider; and finally to address the issues of which type of education best suits the future leaders of this important and rapidly growing sector of activity. In my remarks one will recognise the influence of the many conversations and contacts we have at INSEAD with some of the best and most representative insurance companies in Europe.

The insurance sector is undoubtedly one of the most interesting sectors of economic activity. It provides a vital service to its customers, a service the demand for which grows rapidly with economic development. It deals with a large variety of products and a very diversified customer base, which creates very interesting challenges in marketing, operations management and technology. It is intimately integrated with the financial markets and plays a fundamental and expanding role in the process of channelling savings to investment. And it has almost inevitably to maintain a very long term outlook in its activities, in contrast with the majority of other economic activities, where profitability is often determinated by factors which operate over short periods of weeks or months.

* Text presented at the 22nd General Assembly of the Geneva Association, Lisbon, May 25, 1995.

** Dean of INSEAD, Fontainebleau. 
But the insurance sector has also been, for a long period of time, negatively influenced by two constraints which gave hampered its development: first, a very heavy regulatory environment, which has limited the freedom of action of insurers and prevented the development of a fully competitive atmosphere, leading to more efficient firms and a higher quality of service; second, and not completely unrelated, a very strong national focus, meaning that most insurance companies have operated essentially in their domestic national markets, and implying that, for many of them, internationalisation is now just beginning.

These constraints are now being removed, or have already been removed, in most developed countries and particularly in Europe. Which of course, simply means that the insurance sector is evolving quickly into one of the most rapidly changing industries of today: one in which the forces of deregulation and competition, the trend towards more integrated global markets and the vast options presented by financial innovation all combine with strong growth in the demand of insurance to generate fascinating conditions for business development and for new approaches to management and innovation. However, these developments are not without risks, since not all participants will be winners in the competitive game, the development of the financial markets and instruments often leads to increased uncertainty and the effort to internationalise also brings a far more complex dimension to the management of insurance companies. If educating the leaders of tomorrow is always a challenge, educating the future managers of the insurance sector is a particularly demanding one. And yet, these developments mean that the quality of management will be in the future even more important for the survival and development of insurance companies than it has been until now.

To elaborate a bit longer on how these trends will affect the insurance sector and will determine the needs for education of its managers, let me perhaps focus for a moment on the specially dramatic changes that are taking place in Europe, along the lines I have mentioned. There is no doubt that the most radical progress in European integration over the last few years has happened in the service sector and to a large extent in the financial services sector. After many years of focusing on eliminating the barriers to trade in agriculture and manufacturing, the European Union has more recently extended to services the effort to promote more open and better integrated markets. The Single Market initiative has been and will continue to be a great success; not only have many hidden barriers to competition across borders been reduced or eliminated, but also the search for efficiency gains and quality improvements has generated a powerful drive in the direction of privatisation and deregulation which is transforming the landscape of European services, and in particular financial services. No bank, insurance company or other financial institution can continue sleepily relying on protected markets, on government assistance or on institutional privileges to stay alive. And the opening up of competition and of international markets will undoubtedly continue to lead to a strong restructuring effort, where the most efficient firms will expand through internal growth or through acquisitions, at the expenses of the less competitive players.

Beyond the emergence of more competitive national markets, the most significant new element in this environment is the development of European strategies for many of the key players. As already happened since long ago in many industries, the financial sector is also evolving in the direction of the creation of true European organisations: companies or groups of companies with operations in many different European countries, with employers and shareholders all across Europe, with managers and ultimately boards of directors of 
many European nationalities. In this insurance sector this trend is now just beginning: but I have no doubt that many of the members of the Geneva Association are at this moment planning how to reposition themselves in the vast European market, sometimes through very aggressive acquisition strategies, in other cases through partnerships and alliances which will change structure of the sector in very little time.

The impact of the Single Market is materialising against the background of a more integrated Europe also in the monetary area. The project of Economic and Monetary Union, which seemed just around the corner in 1991, lost most of its momentum in the big exchange rate crisis of 1992/93. But the experience of that crisis has also made the European monetary authorities more prudent or realistic with respect to the importance of establishing the proper convergence conditions before monetary union can take place. And now that the project is regaining interest and that Economic and Monetary Union is again looking feasible, perhaps this new realism will lead to a more robust blueprint, with a better chance of success.

Stable exchange rates, and, eventually, monetary union are extremely important for the integration of European markets. With currency instability, and especially with the volatility of exchange rates that we have witnessed in the recent past, the efficient allocation of resources across Europe will never be possible. If this is valid for all sectors of activity, it is especially true for the financial sector. In no other sector have unstable exchange rates worked more powerfully as a barrier to trade and integration. And the inadequacies and limitations of European financial markets, specially in comparison with North America, can in no small measure be attributed to the segmentation which volatile exchange rates create. The long and arduous road to monetary union is a fundamental component of European integration, is required for the full realisation of the potential of economic progress that we all ambition, and is indispensable to place Europe on a proper level, relative to our competitors in North America and Asia.

But this crucial project can never take place without a degree of monetary and financial discipline which is still not within everybody's reach. If the experience of the last few years has taught us something, it is that without the proper convergence of monetary and fiscal policies monetary union, or simply stable exchange rates will always be a distant dream. As the recession ends and we look forward towards a new period of sustainable growth, there is a general realisation in Europe that macroeconomic policies will have to be geared towards low inflation and tightly controlled government budgets, if we want to keep moving in the direction of monetary integration. And if indeed a small group countries can start monetary union by 1999 , I have no doubt that all others will sooner or later realise the importance of what is at stake and adopt the policies that will eventually allow them to join as well.

This means that we can expect an environment of price stability and more and more disciplined public finances; perhaps not everywhere in Europe, but hopefully in a growing number of countries, as the positive results from convergence towards a demanding standard of performance become gradually and steadily more apparent. As we all know, the implications of this trend to the financial sector and to insurance companies in particular are quite important.

However, since not all countries will be evolving at the same rate, since some will continue to maintain the illusion that independent monetary policies bring advantages, and since co-operation between Europe, North America and Japan in the monetary area is a more 
and more distant goal, it is likely that the monetary integration of a small group of European countries will take place against the background of more currency instability elsewhere in Europe and on a global scale. In today's world of massive capital flows, the major impact of divergence in monetary policy is not really on very different levels of interest rates but rather on highly volatile exchange rates. And as the core of European monetary leaders solidify policies oriented towards price stability, while others continue manipulating monetary policy, hoping for some elusive boost to economic growth, exchange rates will bear the brunt of the adjustment process. Which of course will make the global financial markets perhaps riskier than ever.

After this very brief overview of the dominating trends in the economic environment, what implications can we draw for the insurance sector? How can insurance companies cope with these changing conditions and how should they prepare their managers for this rapidly changing world?

First, the characteristics of the industry imply that, as markets become more open and deregulation takes place, competition becomes far more acute. All studies show that there is no evidence of significant economies of scale in the insurance sector: large companies do not necessarily have a competitive edge over smaller ones. This does not mean that companies will not continue to grow and to search for larger dimension: but this is not the result of an automatic advantage to larger companies - it is simply the result of the fact that more efficient companies will grow faster, sometimes by acquiring smaller ones. Which implies that there is always the possibility of new entrants in the market, prepared to fight for market share, sometimes directly attacking some of the larger more established firms.

And if there are no economies of scale, there seem to be strong economies of scope that is, there is ample evidence that, by combining different services and products, companies can achieve substantial efficiency gains. This is especially visible in the synergy between retail banking and insurance, but is also apparent in the co-operation or alliance between insurers and companies in other sectors, including non financial sectors. Which again adds an element of change and accrued competition in the marketplace. In many countries - and Portugal is actually a good example of this - the structure of the insurance sector has been dramatically altered in the recent past, through increased competition from new companies or from new ventures between insurers and banks, in particular.

As insurance companies have been discovering in recent years, the comfort of strong market position can be very short lived. Competition and innovation can alter the way the business operates, set new standards of service quality and undermine the most solid positions of old and well established companies. Which means that the ability to remain on top of market conditions and to anticipate competitive developments, the agility necessary to adjust rapidly and the flexibility required to enter or exit new segments or markets, as the conditions may recommend, will be more and more the key determinants of success in a far more competitive world.

Insurance companies are also having to develop transnational approaches to their growth strategies. Taking advantage of the much more open and integrated European market will be for many an indispensable element of their development plans. This is of course much more easily said than done. The risks associated with cross border expansion are usually underestimated to quite a large extent. A famous French banker used to say that whenever one of his clients decided to expand into Germany he would swiftly decide to cut all his credit - not because of a lack of opportunities for profitable expansion in Germany, 
but because, in this banker's experience, expansion across borders more often than not resulted in failure. Indeed, the first steps in the direction of internationalisation are always the most painful ones. Even very efficient and strong companies often find that what enabled them to be successful in one country is not at all relevant or appropriate in another. Internationalisation requires an awareness of the subtleties of multicultural management, an ability to adapt to sometimes very different ways of doing business and a fine balance between central control and strategic decision making, on the one hand, and local operational autonomy, on the other hand, which many companies still do not master. The development of competence in transnational management will be one of the decisive sources of competitive advantage in the insurance sector in the future.

The new economic environment, particularly in Europe, will also change the conditions under which insurers will remain profitable and develop. If, as we all hope, the trend towards lower inflation and eventually price stability is to be maintained - and, as I mentioned before, without it all hopes of monetary union will of course vanish - then certainly interest rates will be lower and more stable. Perhaps insurers will welcome this trend, as risks may be lower and financial returns will be more predictable. But on the other hand it will be impossible to hide losses from insurance underwriting through upnormal financial returns. The technical side of insurance management may well become more demanding, since errors will be more easily exposed. Tighter control of costs and more prudent pricing may become far more important than today, which will certainly make the insurance sector more efficient but which will not be without pain for many managers of insurance companies.

The increased discipline of public finances and the further development of large and well integrated capital markets should be very positive for the insurance sector. One of the key consequences of tighter government budgets must be a more realistic assessment of the future of social security. Policy makers are becoming more and more aware of the need to promote reforms which will undoubtedly reduce the scope of social security, and gradually abandon hopes of providing adequate old age pensions for all. As social security evolves in the direction of simply providing a floor for retirement incomes, the demand for private pension plans will undoubtedly grow substantially. This is of course a privileged area for the expansion of insurance business, and many companies are already more and more active in this domain. It may well be that, as happened in North America and in Britain, the development of large scale private pension schemes based on capitalisation as opposed to redistribution will be the strongest possible boost to European capital markets, precisely at a time when they may become more integrated and more efficient. If this is indeed the case, insurance companies may be one of the biggest beneficiaries of a development which will undoubtedly be very positive and significant.

A tighter reign on government finances will also have a positive effect on another important dimension of the development of the insurance sector. Lower government deficits will put less strain on savings and leave more resources available for productive investment. Insurers will more and more have to worry about capital adequacy, and may find that the ability to attract new equity may be a key determinant of their development capacity. As a more competitive environment may lead to narrower profit margins and as rapid growth in the market may require new injections of fresh capital, it is certainly easier to raise new equity when governments are less voracious and absorb lower amounts of private saving than in the opposite case. In our world of frequent and excessive concern with the stimulation of spending to promote short term economic growth, the attitude towards 
saving is often negative or at best careless. I am sure that sectors such as insurance, which will feel the need for capital as a key requirement for long term growth, will appreciate the trend towards lower levels of government debt and the resulting increased availability of private saving.

Finally, as monetary and financial stability will not be generalised, participation in global financial markets will undoubtedly continue to carry large risks. Insurers cannot afford to stay away from these risks, since they will be inherent to the development of more integrated global markets, without which insurance could not grow to the levels that it should. But to participate fully in riskier international markets, insurance companies will have to develop much more than today the full panoply of measurement and control of exposure to risk. As banks and other financial institutions have already done - some with more success than others -, insurers will have to invest significantly in their own systems of risk management, in order to avoid, to the extent possible, the very large scale losses that we have observed in recent years. Financial risk management is a sophisticated domain, requiring solid expertise and also experience; it will be vital for the survival of many insurance companies in the years to come.

Against this background of a rapidly changing environment and a potential for significant development but also of deep restructuring in the insurance sector, what recommendations can we derive for the education of the business leaders of the future? Certainly the sophistication level of management of the insurance sector will continue to increase steadily. Insurance companies will become more and more attractive for top managerial talent, since - much more than what was the case in the traditional past - their management will require and therefore appreciate and reward the highest levels of competence.

In establishing the key requirements of competent management of insurance companies, I would tend to highlight five main areas where expertise may be especially important, as well as a general approach to strategy and organisation.

The first area is undoubtedly finance, and in particular international finance. The need for a thorough understanding of all the intricacies of international financial management will be crucial. The complexity of the new financial instruments, the size of financial markets and the potential for very high volatility, the difficulty of putting in place effective systems to monitor and control exposure to risk lead to almost unlimited demands for expertise in financial management. Often business schools are accused of placing too much emphasis in the study of finance and, in particular, on the more technical or quantitative aspects of financial management. And yet the newspapers are today frequently filled with stories of very large scale losses, sometimes even bankruptcies, in companies where managers did not quite understand the risks they were incurring, did not make proper use of the instruments available to them or failed to control properly the decisions of people in their organisations who had the potential to drive them into bankruptcy. There is no boubt that, if one wants to participate fully in today's financial markets - and, as I argued before, insurance companies do not have much option in this matter - the degree of financial sophistication at all levels of the organisation has to increase dramatically.

But finance is by no means the only area where very sophisticated management will be required. Insurance companies are often very large organisations, serving diverse needs of many different types of customers. As in retail banking, this requires today very competent marketing and management of operations. No insurance company can survive very long 
without taking proper care of its customer base. All aspects of marketing - from the development and maintenance of strong brand names, to very careful pricing policies targeted to rigorously defined market segments, and including a dimension of quality of service which customers require more and more - will be essential ingredients of competent management of insurance companies. The long term nature of many aspects of the insurance business puts a special premium on customer loyalty, which again highlights the importance of marketing to permanently maintain the level of satisfaction of a company's customer base.

In countries where insurers were usually protected from competition, either through regulations or due to positions of quasi monopoly, there is a rather limited tradition of advanced marketing. In those countries, the entry of new competitors with competent marketing strategies is especially easy. And competition will soon show how important marketing becomes when the market is open and customers have choice.

Similarly, the management of operations cannot be neglected. Keeping costs under control while guaranteeing a high quality of service requires complete mastery of operations, and in particular of information technology and systems. Operations management is evolving into a highly advanced domain, where rigour and precision combine with flexibility and adaptability to guarantee affordable service. In financial organisations, operations management is essentially a question of very efficient, reliable and comprehensive information systems. Without them, costs can easily mushroom, there will be insufficient information for appropriate marketing and, above all, it will be impossible to maintain an effort of constant performance improvement.

It is not easy to prepare managers in the area of operations and information systems. Technology evolves very quickly and there are no general recipes or models which can be applied to all situations. Yet, it is in this area that one often finds the success factors behind many cases of outstanding performance on the financial services sector.

Two additional areas seem to be particularly important in the future of insurance management. One is the ability to manage across borders, or across cultures. The other one is the very special competence required to handle mergers, acquisitions or partnerships and alliances.

The international expansion of many insurance companies will require managers who can understand the differences which culture inevitably introduces into business practice. As I argued before, without a good understanding of the implications of culture for management, many well conceived strategies of international expansion end up in failure. It is for this reason that many sophisticated companies now require their managers to have or acquire an international experience, and often send them to educational programmes in an international environment. But beyond the experience, the technical dimensions of culture and management can and should be studied and practised, to minimise the risks of failure in international expansion.

When expansion takes place through acquisitions, partnerships or alliances, corporate culture combines with national culture to bring complexity of managerial problem to an even higher level. Much recent research shows that a large number of mergers and acquisitions lead to poorer performance and that most alliances and partnerships actually fail. This is a difficult area where careful handling of explosive situations is required, so that the full potential of a projected merger or partnership can be realised without the pitfalls that often jeopardise the best plans. In industries where restructuring or reorganisation is happening at a fast pace, the expertise on mergers, acquisitions and partnerships deserves a high premium. 
Finally, let me refer briefly to a broader issue of quality of management, especially relevant to the insurance sector, due to the deep and rapid changes which it is likely to go through. This is the importance of structuring organisations and defining the role of managers in a way that maximises the ability to respond quickly to market changes, to new competition and to technological innovation. A fast changing organisation is not compatible with centralised decision making and with rigid command and control systems. Rather, it requires an approach which maximises the feedback that the market constantly sends to management, and which starts at the level of the customer. Such an approach is based on a high degree of autonomy and power at the lower levels of the organisation, those which are close to the customers, and who are, so to speak, on the battlefront, fighting competition. These must, of course, be high quality people, not mere clerks executing the orders of some distant boss. In such a model, middle managers, instead of exercising control and monitoring the use of resources, become coaches and communicators, guarantecing a cohesive approach and feeding the information back to the top. And top managers essentially provide the general strategic direction and establish the values that will guide the daily decisions of the whole organisation.

Perhaps this model sounds far fetched and unrealistic. However it emerges very frequently when we try to identify the reasons why certain companies are so successful, in spite of having to deal with very fast changing economic environments and with constant threats from new competitors. Perhaps there is here something of relevance for the current as well as the future leaders of the insurance sector. 